\title{
THE APPLICATION RESEARCH OF NATIONAL GEOGRAPHY CENSUS DATA IN THE DEPARTMENTAL INVESTIGATION AND MANAGEMENT-TAKING LAND MANAGEMENT AS AN EXAMPLE
}

\author{
Na Jiang \\ Shandong Provincial Institute of Land Surveying and Mapping, 250102, Jinan, Shandong, China \\ jiangna123321@163.com
}

Commission III, WG III/7

KEY WORDS: National Geography Census Data, Land Management, Land Cover Classification Data, Spatial Transfer Matrix, Geographic National Conditions Monitoring, Yellow River Delta

\begin{abstract}
:
According to the "Natural priority, Status quo priority" principle of acquisition, the national geography census data has the characteristics of objectivity, impartiality and accuracy. It provides a new perspective for the management and decision-making support of other industries as a "third party" and plays an important role in the professional management and investigation of various departments including land, transportation, forestry and water conservancy. Taking land resources supervision as an example, the Yellow River Delta efficient eco-economic zone as the research area, based on the national geographic census data and the land survey data, this paper established the correspondence of the two types of data through the reclassification of the land cover classification data, calculated the spatial coincidence rate of the same land class and the circulation relations among different land classes through the spatial overlay analysis and the calculation of space transfer matrix, quantified the differences between the data and objectively analysed the causes of the differences; On this basis, combined with land supervision hot spots, supplemented by multi-source remote sensing images and socio-economic data, analysed the application of geographic census data in the land regulation from multi-point.
\end{abstract}

\section{INTRODUCTION}

Geographical national conditions reflect the natural, economic, and cultural information of a country from the spatial perspective(Ning and Wang, 2014), involving the territory of the country, geographical divisions, topographic features, road traffic networks, distribution of rivers, lakes and seas, land use, town layout, spatial layout of productivity, etc. It is a comprehensive expression of the natural and human geographic information at the macro level (Chen, 2014; Li et al, 2012). In order to comprehensively investigate and accurately express the status quo of geographic national conditions, the national geographical census data is divided into three kinds: surface morphology, land cover classification, and the important geographic national conditions elements. According to the principle of "natural priority, status quo priority", the data has the characteristics of objectivity, impartiality and high precision.

National geography census data has important differences from departmental thematic data which is concerned about the content of normal operation and social attributes. It provides a new perspective for the management and decision-making support of other industries as a "third party" and plays an important role in the professional management and investigation of various departments including land, transportation, forestry and water conservancy.

With the rapid economic and social development, land use is constantly changing and land resource is becoming increasingly tense. The land administration has continued to strengthen the supervision of land, and the monitoring of land resource has been a research hotspot. Bao et al(Bao, 2003; You, 2009; Zhang et al, 2012; Yang et al, 2014) extracted land use information from remote sensing images for dynamic monitoring through different information extraction methods; Zhang et al (Zhang and Xiong, 2008; Zhong et al, 2009; Cao et al, 2013)combined remote sensing and GIS technologies to analyze the spatial structure changes of land use; Wan et al (Wan et al, 2005; Qiao et al, 2013) monitored land use evolution based on land use transfer matrix. Some of the researches that have been conducted used low resolution image as the data source in large area monitoring, which were difficult to meet the requirements of fine-scale land use supervision; or they only monitored based on the interpretation of remote sensing, and paid less attention to the social attributes of land. In the actual land resource supervision, it is necessary to use professional data of the land department as the management basis, and the high-precision "third-party" data is also required as the supplement to supervise the results of land surveys. Taking this as a starting point, this paper was based on national geography census data and land use survey data, through the comparison and analysis of two types of data, to clarify the relationship of data, verify the characteristics of national geography census data and explore the application and service direction. On this basis, it could promote the in-depth application of national geography census data in the investigation and management of land and other sectors.

\section{RESEARCH METHOD}

The method of research in this paper is described as follows.

\subsection{Reclassification of land cover classification data}

First, we analysed the relationship between geographical national surveys and thematic change surveys. Through the analysis and comparison of national geography census data and 
land use survey data, including principles of the classification, differences of the contents and the spatial coordinate systems, this paper determined the correspondence between the two types of data and reclassified the national geographic census data to the land use data system. Here, the land cover classification data (hereinafter referred to as LCA) in the national geography census data and the land parcel data (hereinafter referred to as DLTB) in land survey data were used to analysis. According to the corresponding relationship, the LCA was reclassified to the land use classification system.

\subsection{Data consistency analysis}

Coordinate the spatial datum of the two types of data, and convert the land use data from $1980 \mathrm{Xi}$ 'an coordinate system to the 2000 national geodetic coordinate system; Perform spatial overlay and statistical analysis, and calculate the spatial coincidence rate of the same type of land.

\subsection{Spatial transfer matrix analysis}

The land use change transfer mode (Zhang, 2008) was used to calculate the source-direction matrix from LCA to DLTB, and to analyse the reason of discrepancy. To ensure the speed of calculation, the two types of data were rasterized before analysed.

\subsection{Application in land use and supervision}

Through the in-depth analysis of the two types of data relationships, combined with the hot spots of land administration, supplemented by multi-source remote sensing images and socio-economic data, etc., the application of national geography census data in land supervision was analysed from multiple aspects.

The technical flow chart is shown in Figure 1.

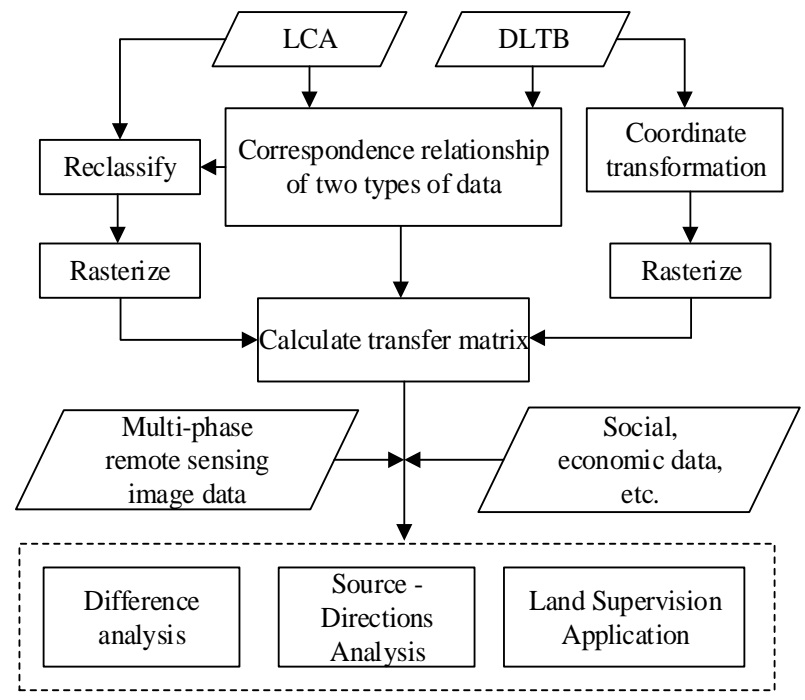

Figure 1. Technical flow chart

\section{EXPERIMENTS AND ANALYSIS}

\subsection{Study area and data}

The study area in this paper is the Yellow River Delta High Efficient Ecological Economic Zone (hereinafter referred to as the Yellow River Delta). The Yellow River Delta is an economic zone formed by expanding to the periphery based on the historical alluvial plain of the Yellow River and the coastal areas of northern Shandong Province. It includes all the Dongying and Binzhou cities and their adjacent areas which have the similar natural and environmental conditions, such as Hanting district, Shouguang city, Changyi city in the northern part of Weifang; Laoling, Qingyun County in Dezhou, Gaoqing County in Zibo, and Laizhou city in Yantai. The research area involves a total of 19 counties (cities, districts) in 6 cities, with a total area of 26,500 square kilometers, accounting for onesixth of Shandong province. The Yellow River Delta is one of China's three major deltas and an important part of the Bohai Rim economic circle. In 2009, the Yellow River Delta became a national strategy and one of the main battlefields for the rapid development of efficient ecological economy. However, the Yellow River Delta's eco-environment is relatively fragile, and the land use change is fast. Therefore, it is of great importance to effectively supervise the land use in the area, so this paper takes the area as the research area.

The national geography census data used in the experiment was produced in year 2015 and mainly included land cover classification data and geographic national conditions elements data. Among them, the land cover classification data (LCA) has about 1.83 million map spots, including 10 first-class categories, which are cultivated land (0100), garden land (0200), forest land (0300), grassland (0400), house building district (0500), roads (0600), structures (0700), artificial excavation sites (0800), deserts and exposed surfaces (0900), and water areas (1000). On this basis, they are subdivided into 46 secondary classes and 79 tertiary classes. The data uses the 2000 national geodetic coordinate system, latitude and longitude coordinates. Land use data was extracted from the 2014 land change survey data. It was based on the land use survey results and initial cadastral results, and updated based on the annual changes in land registration and land statistics to meet the demands of land management. The land use data of the Yellow River Delta came from the Ministry of Land and Resources, with a total number of 986,000 land parcels. The data is divided into 8 categories such as cultivated land ( 01 , hereinafter referred to as CLand), garden land (02, hereinafter referred to as GLand), forest land (03, hereinafter referred to as FLand), grassland (04), urban villages and industrial land (20, hereinafter referred to as ULand), transportation land (10, hereinafter referred to as TLand), water areas and water conservancy facilities land (11, hereinafter referred to as WLand) and other land (12, hereinafter referred to as OLand). They are further divided into 30 second-class categories according to their operating characteristics, utilization patterns, and coverage characteristics. The data used 1980 Xi'an coordinate system, Gauss-Kruger 3 degree projection, and took $120^{\circ}$ as the central meridian. In addition, the 2010-2015 Land change survey remote sensing image data was used as the base map for the analysis. Most of these images were multi-spectral data with 0.5 -meter spatial resolution, partially 0.5 -meter panchromatic imagery or better than 2 meters multi-spectral data. The acquisition time is 10-12 months each year. The 2014-2015 $0.5 \mathrm{~m}$ resolution aerial photography images and 2013-2015 2m resolution multispectral data of Mapping Satellite-1, Resources Satellite-3 were used as supplementary analysis data.

\subsection{Built up the correspondence of data systems}

Since the LCA and DLTB are independent data, the two types of data do not correspond one by one. Therefore, in the process 
of data analysis, the corresponding relationship must be established first. In the process of establishing correspondence relationship, according to the principles of "consistent in content meaning, consistent in spatial reference, and consistent in data statistical methods", with the reference of land use data, the land cover classification data was reclassified into the land use classification data system, as shown in Table 1 which took arable land as an example. Full coverage method was used to complete the comparison of the whole classification system. For the classes that could not be matched one-by-one, according to the "major correspondence" principle, encoded them as the mainly related class. The area of all categories should not be recalculated or omitted. The meanings of classes with the same name in the two classification systems may not be exactly the same, and the correspondence relationship should be based on the actual meaning of the classes. At the same time, the correspondence relationship was based on the consistency between subclasses. Upper level were merged hierarchically according to subclasses.

\begin{tabular}{|c|c|c|c|c|c|c|c|}
\hline \multicolumn{2}{|c|}{ Land Use Data Classification } & \multicolumn{3}{|c|}{$\begin{array}{c}\text { Corresponding National } \\
\text { Geography Census Data } \\
\text { Classification }\end{array}$} \\
\hline First Class & \multicolumn{2}{|c|}{$\begin{array}{c}\text { Secondary } \\
\text { class }\end{array}$} & \multicolumn{2}{|c|}{ First Class } & Secondary class \\
\hline Code & Name & Code & Name & Code & Name & Code & Name \\
\hline 01 & 011 & $\begin{array}{c}\text { Paddy } \\
\text { Field }\end{array}$ & 0100 & $\begin{array}{c}\text { Cultivated } \\
\text { Land }\end{array}$ & 0110 & $\begin{array}{c}\text { Paddy } \\
\text { Field }\end{array}$ \\
\cline { 3 - 8 } & Land & $012 /$ & $\begin{array}{c}\text { Irrigated } \\
\text { land / } \\
\text { Dry } \\
\text { Land }\end{array}$ & 0100 & $\begin{array}{c}\text { Cultivated } \\
\text { Land }\end{array}$ & 0120 & Dry Land \\
\cline { 4 - 8 } & 013 & Structure & 0750 & Greenhouse \\
\hline
\end{tabular}

Table 1. Correspondence of two types of data (cultivated land)

\subsection{Experiment analysis}

3.3.1 Data difference analysis: Calculate the area of each primary class in the DLTB data and calculate the area of the first class of land use data which was reclassified from LCA data. The land use data was transformed to the 2000 national geodetic coordinate system, and the spatial overlay analysis of the two types of data was performed in ArcGIS. Calculate the ratio of the same type of overlapping area to the first class of land use data.

The corresponding relationship between the two types of data is shown in Figure 2. The overall coincidence rate was $62 \%$. Among them, CLand had the highest and most stable coincidence rate, about $78 \%$; followed by ULand, about $72 \%$. OLand had the lowest coincidence rate, only $6 \%$. From the perspective of spatial location, the coincidence rate raised from the coast to the Inland, as shown in Figure 3. There are four main reasons for the existence of differences. The first reason is the difference in data collection principles. The national geography census focus on natural attributes, while land use surveys focus on management and social attributes. For example, due to seasonal changes, economic benefits of planting, shortterm use of land contractors, etc., land use may be temporarily changed, but land use data classes do not change; but In the national geography census, according to the status of the natural surface coverage at the time of its collection, it was assigned to the corresponding category, as shown in Figure 4. The second reason is that there are differences in the definitions of the same class in national geography census and land survey. Take the road definition as an example. In the national geography census, road pavements with the width of more than 3 meters and the length of more than 500 meters should be collected. In the absence of vegetation coverage, this contains the range of the embankment and the cut. The transportation land in land survey includes "embankments, cuts, road ditch, bridges, car stops, forests, and ancillary land directly served for the road" in the design. As shown in Figure 5, the road widths in the national geography census are mostly less than the road widths in the land use surveys. The third reason is that the data collection scales and the comprehensive principles are inconsistent. The strips such as grassland, road pavement, and impervious surface that meet the acquisition criteria in the land cover data may be incorporated into the nearby category in land use, as shown in Figure 6. The fourth reason is the inconsistent of data collection date. The acquisition time of land use data is 2014, and the land cover data is 2015 . The inconsistency of data time results in the change of actual land features. In addition, there is no one-toone correspondence between the two types of data, and there are various relationships such as one-to-many, many-to-one, and many-to-many correspondences. All of these cause differences in the statistical results of the two types of data.

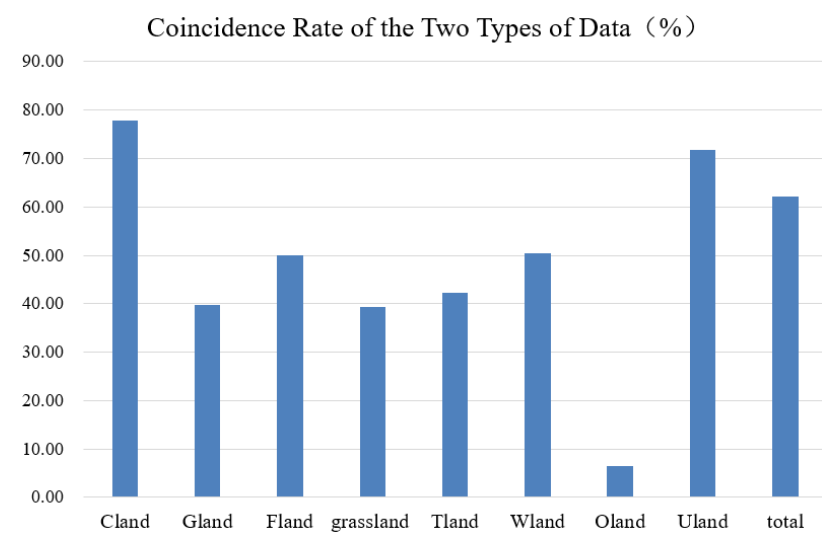

Figure 2. Corresponding relationship between the two types of data

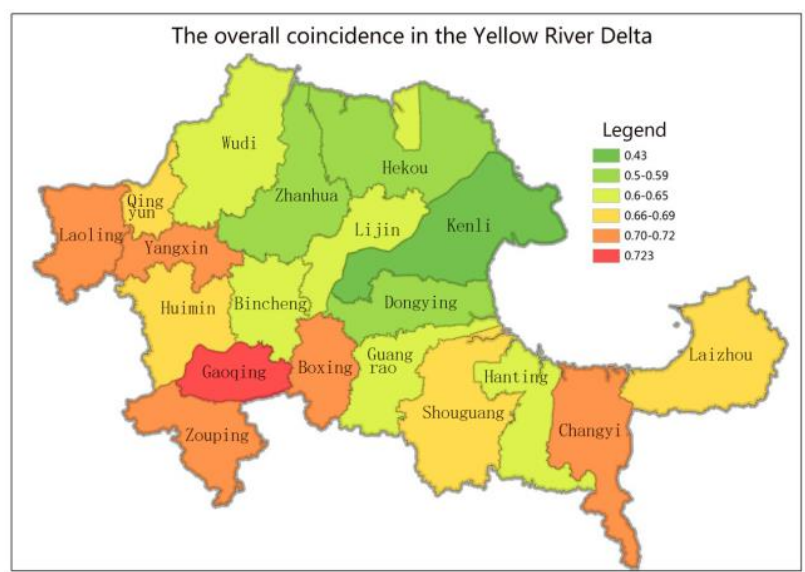

Figure 3. The overall coincidence in the Yellow River Delta 


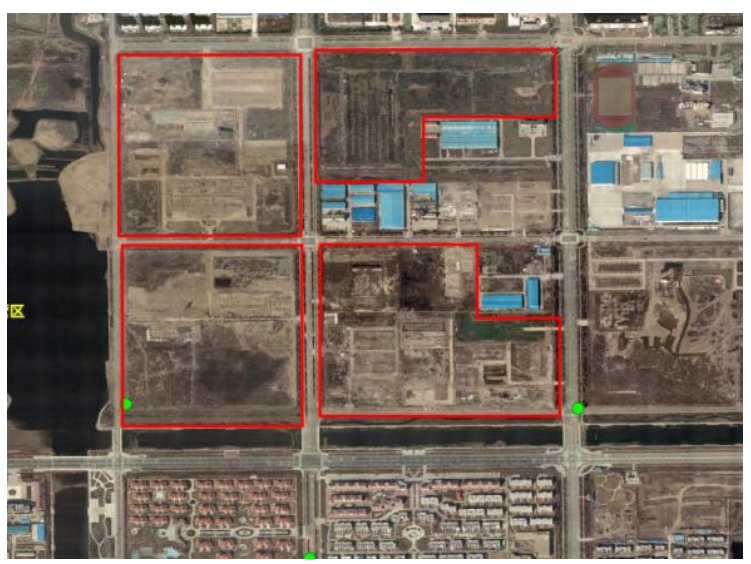

(a)

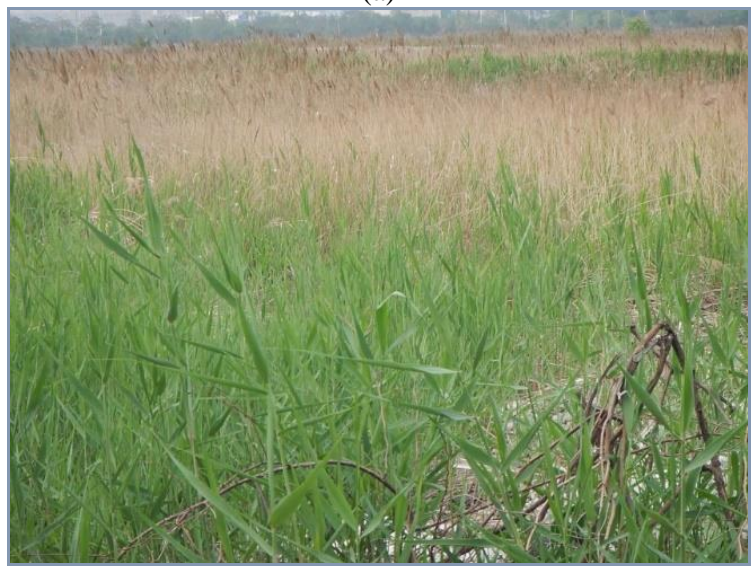

(b)

Figure 4. Inconsistent collection of the same object in two types of data (a) Construction land in DLTB, grassland in LCA; the red lines are the boundaries; the green points are the sample points (b) Field photos of sample points

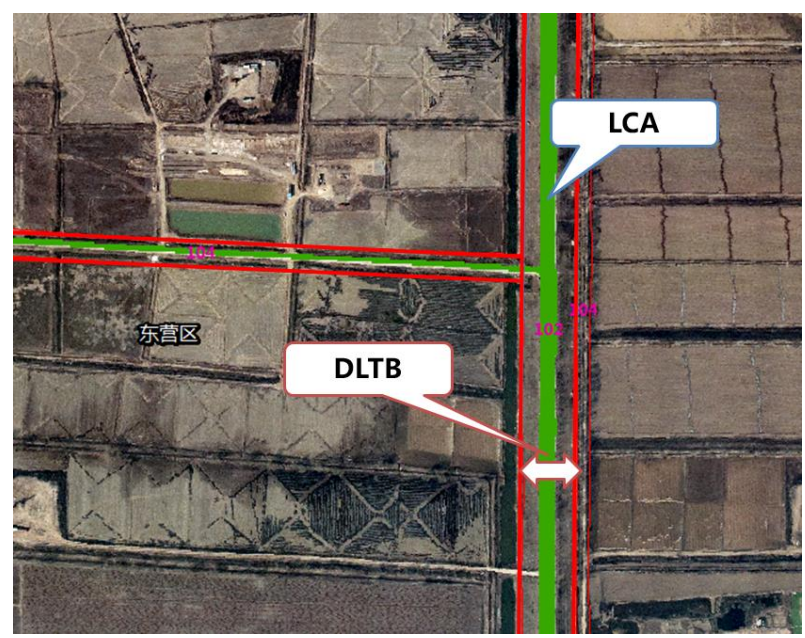

Figure 5. Inconsistent definition of road range in land use and land cover

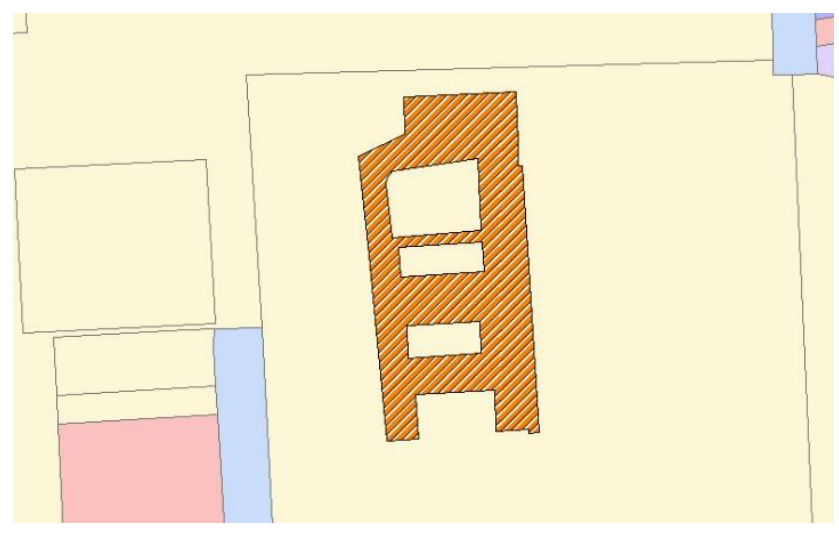

Figure 6. The impervious surface (the orange slash part) in LCA was integrated in the DLTB

3.3.2 Source - Direction Analysis: On the basis of the qualitative analysis of the two types of data relationships, the conversion relationship between the data is quantitatively calculated by source-direction analysis. In order to improve the calculation efficiency, the two types of data were rasterized with a grid size of 2 meters, and the source-and-direction matrix was calculated in the software of ArcGIS. Take Dongying City as an example. The result was shown in Table 2. The relationship between the two types of data in the Yellow River Delta with a difference of more than $200 \mathrm{~km}^{2}$ and the conversion relationship was shown in Figure 7. In the DLTB-to-LCA transformation, CLand, WLand, OLand were mainly transferred out, and FLand and grassland were mainly transferred in. The FLand increased in the LCA data mainly came from the CLand and WLand of DLTB. The extra part came from each class, which mainly came from CLand, WLand and OLand. In the transformation relationship of more than $200 \mathrm{~km}^{2}$, the bidirectional relationship were distributed among OLand to WLand, ULand to WLand, and CLand to GLand. The differences between the two types of data in the Yellow River Delta region that is greater than $500 \mathrm{~km}^{2}$ were that the CLand in DLTB was collected as forest land and grassland in LCA; the WLand was collected as grassland, and OLand was collected as grassland. With regard to the relationships among the main agricultural lands in the three major categories of CLand, GLand and FLand, from DLTB to LCA, the CLand was mainly transferred out; FLand was mainly transferred in, and the total amount of GLand remained basically balanced. The main differences between the two types of data in the coastal four counties of Dongying were the conversions of OLand, grassland, and WLand. The transformation relationships between Shouguang City and Hanting District were mainly the differences and conversions between OLand/WLand and ULand. The difference in Zhanhua County was mainly that the CLand was turned into Gland, and the conversion of CLand to FLand/grassland was mainly in Wudi County, Qingyun County, and Bincheng District. The remaining counties were mainly CLand to FLand. The situation of CLand transferred in and out in the Yellow River Delta is shown in Figure 8. The difference and the spatial distribution between the two types of data has obvious correlation, showing a certain group characteristics. This may be influenced by a combination of factors such as its geographical location, natural resources, local cities, development planning, and economic and land policies. 


\begin{tabular}{lrrrrrrrr}
\hline $\begin{array}{l}\text { LCA } \\
\text { DLTB }\end{array}$ & 01 & 02 & 03 & \multicolumn{1}{c}{04} & 10 & 11 & 12 & \multicolumn{2}{c}{20} \\
\hline 01 & 1859.4 & 22.0 & 155.0 & 165.5 & 13.0 & 20.6 & 2.7 & 62.5 \\
02 & 18.3 & 8.89 & 10.6 & 1.5 & 0.34 & 0.3 & 0.0 & 2.6 \\
03 & 37.4 & 2.1 & 76.7 & 70.6 & 1.3 & 18.7 & 20.1 & 4.6 \\
04 & 74.2 & 0.1 & 5.3 & 49.3 & 0.6 & 7.6 & 3.8 & 5.1 \\
10 & 10.2 & 0.4 & 30.2 & 37.9 & 63.8 & 9.1 & 2.2 & 19.1 \\
11 & 272.7 & 6.4 & 89.4 & 547.6 & 39.9 & 1522.1 & 471.2 & 219.6 \\
12 & 283.8 & 3.1 & 48.5 & 489.9 & 13.5 & 199.6 & 108.1 & 164.9 \\
20 & 29.29 & 1.58 & 43.79 & 111.62 & 42.85 & 26.79 & 9.22 & 607.6 \\
\hline
\end{tabular}

Table 2. Source - Direction matrix of LCA and DLTB of Dongying City (Area Unit: $\mathrm{km}^{2}$ )

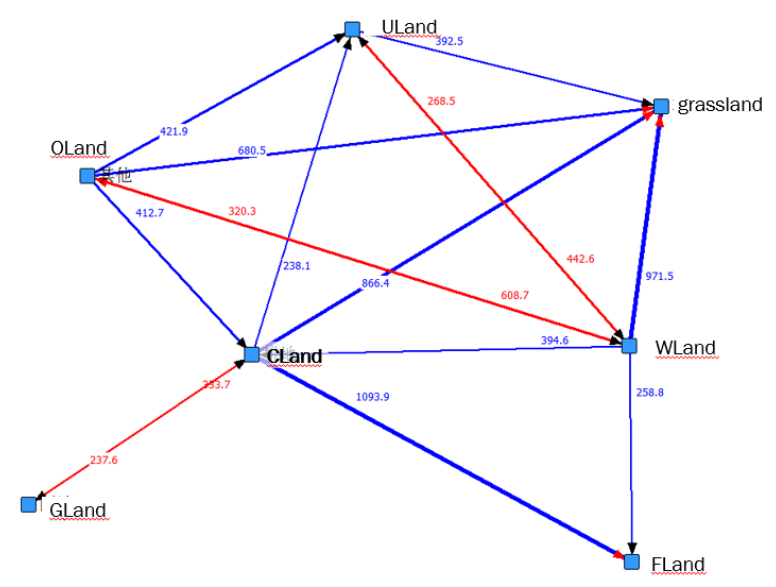

Figure 7. Classes that the conversion relationships more than $200 \mathrm{~km}^{2}$ in the Yellow River Delta

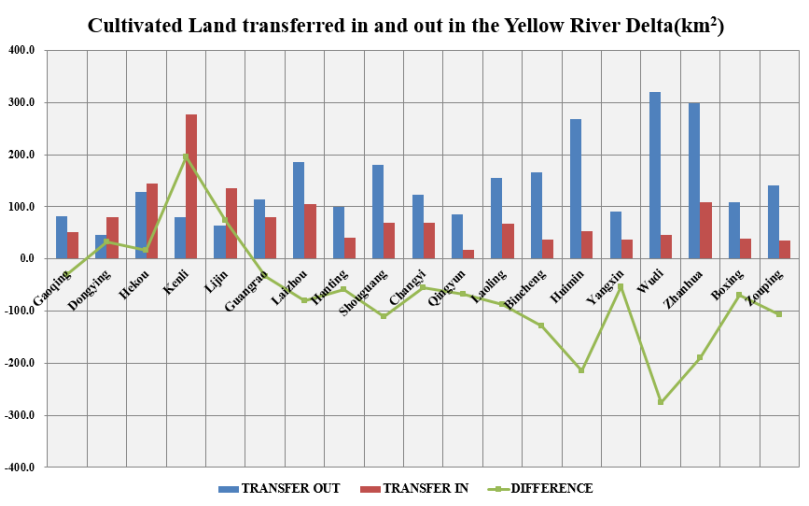

Figure 8. Cultivated Land transferred in and out in the Yellow River Delta
3.3.3 Application in land supervision: Through in-depth analysis of the two types of data, the objective and detailed characteristics of the national geography census data were highlighted. Combining with the land use hotspots, this paper proposes that geographical national survey data has several application points in land supervision. First, the correspondence between CLand in the two types of data is the most clear. The emphases is different in the different data system. The LCA data can be used as a third-party data to monitor and analyse the transformation of CLand. Through the analysis of the sourcedirection of the CLand, we found out the distribution of suitable land for agriculture and reassessed the suitability of land use. In particular, administrative department should pay attention to the phenomenon that a large amount of spontaneous reclamation of CLand. For example, there were a large number of OLand (saline land) turning into CLand in the Kenli County Yellow River estuary. Secondly, the impact of human construction activities on the land including not only the conversion of nonconstruction land to construction land, but also the conversion of cultivated land from agricultural land to garden/forest land should also receive enough attention. Of the cultivated land transferred, $78 \%$ were converted into nurseries and $22 \%$ of them were young artificial forests. The CLand converted into FLand and GLand may be due to the economic construction activities which could bring more compensation benefits. Attention should be paid to the construction field, or the artificial young forest, nursery garden, natural grass around the town or regularly shaped. Such regions may be the next hot area of construction. Thirdly, the LCA data can supervise the use of urban construction land. It can play the role of regulatory in the progress of construction, construction and planning in line with the situation and the status approved but no construction. The large natural grassland within the town, especially the natural grassland with large area and regular shape, can reflect the use of construction land within the city, such as the suspected area that was not used after approval (shown as Figure 4). Through the comparison of planned land use and actual land cover, it could be judged whether the construction progress conformed to the plan. Fourthly, it could track the sources of new construction land. According to the analysis of the sources of construction fields, it was found that the construction fields in the Yellow River Delta mainly coming from ULand (39\%), followed by WLand (21\%), then the CLand (16\%), shown as in Figure 9. In the monitoring process, through the analysis of multiple periods of data transformation, hot spots and key directions in urban construction could be found.

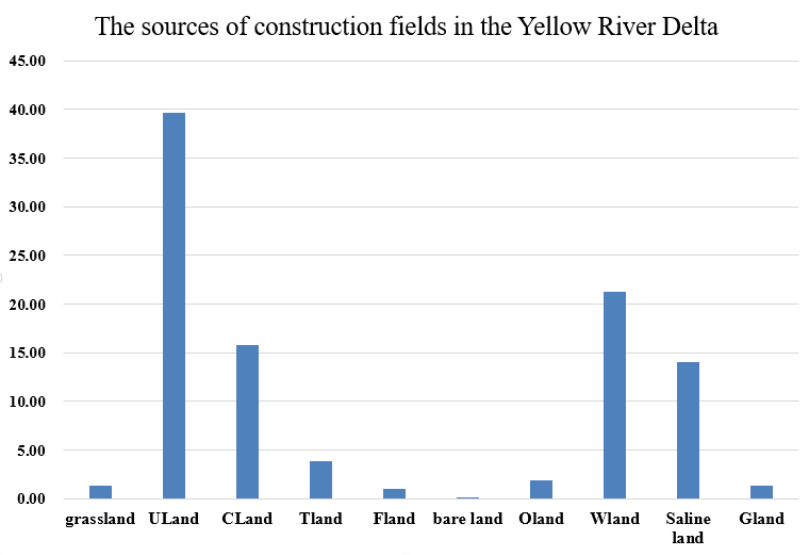

Figure 9. The sources of construction fields in the Yellow River Delta 


\section{CONCLUSIONS}

The national geography census is application-oriented. Through the comparison and analysis of the land use data and land cover classification data, this paper discussed the application of national geography census data in land supervision. The objective and meticulous characteristics of the census results provide a platform for monitoring and supervising the land census, and its results can also play an important role in land management. With the comprehensive application of the national geographical census and the implementation of normalized geographic national conditions monitoring, he geographic national condition data will play an increasingly important role in the management and application of more and more government departments.

\section{REFERENCES}

Bao, G.Y., 2003, Application of Different Methods of Extracting Varying Information to Dynamic Remote Sensing Monitoring of Land Use, Bulletin of Surveying and Mapping, 8, pp. $38-40$

Cao, Z.J., Wu, X.Y., Gao, Z.Y., et al, 2013, Land Use Dynamic Remote Sensing Monitoring Region Partitioning Method Based on the Development Pressure State: A Case Study of Jinnan District, Tianjin City, Remote Sensing for Land and Resources, 25(3), pp. 124-129

Chen, J.Y., 2014, Study Notes on Geographic National Condition Monitoring, Acta Geodaetica et Cartographica Sinica, 41(5), pp. 633- 635

Li, D.R., Sui, H.G., Shan, J., 2012, Discussion on Key Technologies of Geographic National Conditions Monitoring, Geomatics and Information Science of Wuhan University, 32(5), pp. 505-512

Ning, J.S., Wang, Z.T., 2014, Comprehensive report on development of 2012-2013 surveying and mapping, Science of Surveying and Mapping, 39(2), pp. 3-10

Qiao, W.F., Sheng, Y.H., Fang, B., et al, 2013, Land Use Change Information Mining in Highly Urbanized Area Based on Transfer Matrix: A Case Study of Suzhou, Jiangsu Province, Geographical Research, 32(8), pp. 1497-1507

Wan, J.B., Zhu, G.R., Peng, Q.G., 2005, Land Use Information Tupu and Its Application, Geomatics and Information Science of Wuhan University, 30(4), pp. 355-358

Yang, Y., Xu, L., Yan, P.L., 2014, Urban Land Use/Cover Classification of Remote Sensing using Random Forests under the Framework of Conditional Random Fields, Remote Sensing for Land and Resources, 26(4), pp. 51-55

You, S.C., 2009, Landuse Change Detection Based on CCD Data of CBERS-02B, Remote Sensing Information, 2, pp. 2328

Zhang, F.F., Li, W.Z., Lu, L.Y., 2012, Technologies of Extracting Land Utilization Infromation Based on SVM Method with Multi-Window Texture, Journal of Remote Sensing, 16(1), pp. $73-78$
Zhang, X.C., Xiong, X.C.,2008, Research of Spatial Structure of Land Use Change Based on RS/GIS Technology, Acta Scientiarum naturalium Universitatis SunYatsen I, 47(3), pp. 117-121

Zhong, K.W., Sun, C.G., Xie, L., 2009, The Dynamic Monitoring of Land Use Change in Guangzhou Based on RS and GIS, Journal of Geo-Information Science, 11(1), pp. 111116 